\title{
PERFIL, HÁBITOS DE CONSUMO E MOTIVAÇÕES DE COMPRA: UMA PESQUISA DE MERCADO APLICADA AO SETOR DE BIJUTERIAS
}

PROFILE, CONSUMER HABITS AND PURCHASE MOTIVATIONS: A MARKETING RESEARCH APPLIED TO THE BIJOUTERIE SECTOR

Recebido em 27.05.2016. Aprovado em 11.11.2016

Avaliado pelo sistema double blind review DOI: http://dx.doi.org/10.12712/rpca.v10i4.770

\section{Danielle Ferreira de Melo}

melo.daniy@gmail.com

Universidade Federal de Alagoas (UFAL), Maceió/AL, BRASIL

\section{Gustavo Henrique Silva de Souza}

souza.g.h.s@hotmail.com.br

Instituto Federal do Norte de Minas Gerais (IFNMG), MG/BRASIL

\section{Antonio Carlos Silva Costa}

acscosta@gmail.com

Universidade Federal de Alagoas (UFAL), Maceió/AL, BRASIL

\section{Nilton Cesar Lima}

cesarlim@yahoo.com

Universidade Federal de Uberlândia (UFU), Uberlândia/MG, BRASIL

\section{Resumo}

Este artigo teve por objetivo investigar o comportamento de consumidoras de bijuterias, no que diz respeito a perfil, hábitos de consumo e motivações de compra. Para tanto, foi realizado um estudo descritivo e de abordagem quantitativa, em que foram aplicados dois instrumentos de pesquisa em uma amostra não probabilística por conveniência de 202 mulheres brasileiras consumidoras de bijuterias. Por meio de análises de estatísticas descritivas de parametrização simples e do teste t de Student, foram encontrados resultados que denotam a predominância dos seguintes aspectos: (1) o consumo de bijuterias se concentra na faixa etária entre 15 e 35 anos de idade; (2) classes sociais não interferem nos hábitos de consumo de bijuterias; (3) há preferência por compras em boutiques e lojas de departamento; (4) as compras de bijuterias ocorrem, em geral, quando os preços e condições de pagamento são satisfatórios ou quando há necessidade; Apesar disso, (5) as consumidoras costumam ir mais de uma vez por mês em lojas de bijuterias; (6) levam mais de um tipo de produto por compra; e (7) priorizam preço e durabilidade. Este estudo permite o acesso profícuo à estrutura das relações de compra e esclarece elementos específicos que perfazem possíveis padrões de consumo no mercado brasileiro de bijuterias.

Palavras-chave: Consumo. Bijuterias. Público Feminino. Estratificação Social. 


\section{Abstract}

This article aimed to investigate the behaviour of bijouterie consumers, with regard to profile, consumer habits and purchase motivations. To this end, we performed a descriptive study with a quantitative approach, in which two research instruments were applied in a non-probabilistic convenience sample of 202 Brazilian women consumers of bijouterie. Using descriptive statistical analysis of simple parameterization and the Student t test comparing average scores of sub-sample 1 (classes $\mathrm{C}$ and D) and the sub-sample 2 (classes A and B), we found results that denote the predominance of the following aspects: (1) the bijouterie consumption is concentrated in the age group between 15 and 35 years old; (2) social classes do not interfere in bijouterie consumption habits; (3) they prefer to shop in boutiques and department stores; (4) the bijouterie purchases occur in general when prices and payment terms are satisfactory or when there is need; Nevertheless, (5) they usually go more than once a month in bijouterie shops; (6) they buy more than one kind of product by purchase; and (7) they prioritize price and durability. This study enables profitable access to the purchasing relationships structure and clarifies the specific elements that make up possible consumption patterns in the Brazilian bijouterie market.

Keywords: Consumption. Bijouterie. Female Consumers. Social Stratification. 


\section{Introdução}

No mercado competitivo atual, a concepção de moda - considerando-a em uma perspectiva comercialmente e culturalmente aceita e adotada por consumidores vem remodelando os padrões comportamentais de consumo e transformando as ambiências tecnológicas (RENNÓ; TEIXEIRA, 2008; SILVA et al., 2014). Conforme Cobra (2007) explica, a moda é composta por um único fator constante: a mudança. Basicamente, tem-se o estabelecimento de noções de eficiência produtiva e padronização da qualidade associada a um tipo específico de estratégia: a personalização diferenciação e criação de valor (CUNHA; CUNHA; MONTE, 2015).

Este é o cenário corrente do setor de bijuterias caracterizado por semijoias e acessórios produzidos com ligas metálicas, pedras semipreciosas ou de vidro e plástico, etc. -, que vem apresentando um crescimento gradual notório no mercado global, em âmbito social e econômico (VINENT, 2011; OLIVEIRA; GIL, 2014; ZAMBON; ANUNCIAÇÃO, 2014). De acordo com Palma et al. (2014) e Sousa (2015), há uma conjuntura de variáveis explicativas para essa situação, como o aumento do poder de compra das classes $\mathrm{C}$ e $\mathrm{D}$, ou o surgimento de uma cultura de consumo bastante idiossincrática por semijoias e acessórios derivados. Além disso, desde o início do século $\mathrm{XX}$, vem se denotando valores mais altos de comercialização para pedras e metais preciosos, em detrimento de custos de produção mais expressivos na cadeia produtiva. Consequentemente, o mercado de joias tende a apresentar oscilações mais aparentes e dar lugar ao crescimento exponencial do mercado alternativo/ substituto de bijuterias (ver, SAMPAIO, 2002).

Embora as bijuterias apresentem ciclo de vida e qualidade inferiores às joias, as bijuterias são mercadologicamente mais viáveis, em termos de custos de produção e adequação aos preceitos básicos da moda competitiva (montagem, design, manuseio e personalização) (ver, SILVA, 2007; ALBERTON, 2011). Rodrigues (2013) e Casals (2014) ressaltam que, apesar dos diferenciais competitivos de qualidade e preço, o setor de bijuterias ainda tenta se firmar no mercado, o que torna indispensável conhecer o público-alvo de bijuterias - em função das necessidades e hábitos de consumo -, especialmente porque o setor é predominantemente baseado na informalidade e em baixos níveis de inovação (ver, DI GIULIO, 2007; PIMENTEL et al., 2011).
Alguns estudos (p.ex., SCHLÜCKING, 2000; SILVA, 2004; CAETANO, 2006; FARACO, 2010; RODRIGUES, 2013; CASALS, 2014), de forma contraintuitiva, têm encontrado resultados de que a difusão de acessórios de bijuterias não está somente ligada a adolescentes e jovens, nem a classes sociais mais baixas, embora convirja para a predominância do público feminino. Na verdade, o setor de bijuterias tem se globalizado e vem ganhando espaço em variados clusters populacionais (ver, MODANEZ et al., 2009).

No entanto, faltam estudos que avaliem o comportamento do consumidor de bijuterias quanto aos aspectos de segmentação sociodemográfica e psicográfica. De tal modo, este artigo tem por objetivo investigar o comportamento de consumidoras de bijuterias, no que diz respeito a perfil, hábitos de consumo e motivações de compra. Além disso, buscar-se-á encontrar simetrias e/ou diferenças entre o comportamento das consumidoras através da estratificação por classe social.

O foco no público feminino segue recomendações da literatura, que indicam que a intenção e a propensão à compra de bijuterias são prevalentes em consumidores do sexo feminino (PIMENTEL et al., 2011; LACORTE et al., 2013; GOULART; CARVALHO; RIBEIRO, 2014), além das propagandas e campanhas promocionais de empresas de bijuteria estarem quase que exclusivamente concentradas em mulheres (GOULART; RIBEIRO; CARVALHO, 2014; CUNHA; CUNHA; MONTE, 2015). Logo, a avalição do público feminino pode permitir o acesso mais profícuo à estrutura das relações de compra e compreender com acurácia padrões de consumo no mercado brasileiro de bijuterias.

\section{O Mercado Brasileiro de Bijuterias}

O mercado brasileiro de bijuterias possui muitas características peculiares, segundo Goulart, Carvalho e Ribeiro (2014), especialmente devido ao caráter multicultural do país e à valorização da moda internacional, que permitem o surgimento de diversos grupos consumidores diferentes. Por sua vez, na visão de Bertoncello e Crescitelli (2009), esses grupos configuram-se em distintas estruturais sociais e culturais, não se obtendo um perfil padronizado ou homogeneizado. 
As tendências de consumo apontam para a necessidade preeminente de personalização e baixos custos (CUNHA; CUNHA; MONTE, 2015). Ademais, inúmeras oportunidades decorrentes do crescimento acelerado do mercado de bijuterias e acessórios femininos têm colocado o setor em uma posição de destaque na economia mundial (PALMA et al., 2014). Segundo Noronha et al. (2017), entre 2013 e 2015, o setor de bijuteria cresceu em média $10 \%$ ao ano mais do que outros setores da economia. Apesar disso, Di Giulio (2007) afirma que o setor de bijuterias, há muitos anos, vem crescendo desordenadamente, com bastante informalidade e pouca inovação.

De acordo com o Instituto Brasileiro de Gemas e Metais Preciosos (IBGM, 2014), a difusão da comercialização de bijuterias em âmbito internacional pode ser justificada pelo aumento da produção, pela acessibilidade de preço e pelas apostas na diferenciação por qualidade dos acessórios, bem como por um design mais incrementado e diversificado. Por outro lado, a expansão significativa do mercado brasileiro deve-se, principalmente, ao crescimento do número de consumidores das classes C e D. Isto é, a produção de bijuterias no Brasil vem predominantemente acompanhando o crescimento do mercado doméstico, que tem a sua evolução em função do volume de vendas.

Segundo o IBGM (2014), o setor de joias, gemas e bijuterias obteve um crescimento positivo de $38 \% \mathrm{em}$ seu faturamento no ano de 2012 em comparação ao ano 2011 - faturamento de $\mathrm{R} \$ 7,5$ bilhões, sendo 40\% referente ao setor de varejo. Dentre os setores, apenas o de joalherias obteve uma queda de $3,4 \%$, que pode ser explicada pela alta no preço do ouro. Os demais setores obtiveram crescimentos positivos de $12 \%$ (mineração), $11,1 \%$ (folheados e bijuterias), $8,3 \%$ (outros) e $6,3 \%$ (lapidação e artefatos de pedras). No Brasil, a cidade de Limeira (SP) concentra 60\% dos produtores de bijuterias nacionais, com uma capacidade produtiva de cerca de $\mathrm{R} \$ 460$ milhões por ano.

Segundo Zambon e Anunciação (2014), as micro e pequenas empresas (MPEs) são predominantes no setor de bijuterias, evidenciando o surgimento de variadas redes de cooperação entre empresas, que buscam um posicionamento estratégico em específicos contextos locais. No entanto, devido às características peculiares do setor brasileiro de bijuterias, como o foco no mercado interno e baixos padrões de qualidade, o que restringe a progressão nas exportações, limitando a competitividade das empresas no cenário interno.
Mais especificamente, Faraco (2009) esclarece que o setor de bijuterias é sempre atrativo em função de uma necessidade pré-histórica pelo uso de adereços, enfeites, adornos e acessórios, que tende a permanecer com um significado psicossocial muito forte - uma simbológica social, cultural e religiosa - especialmente para o público feminino (ver, FIGUEIREDO; TRAPÉ, 2007; GOULART; RIBEIRO; CARVALHO, 2014), acarretando em ganhos econômicos para o mercado.

Considerando esses aspectos, Zambon e Anunciação (2014) explicam que as bijuterias passaram a ser caracterizadas como acessórios alternativos, substitutos diretos das joias e metais preciosos significativamente mais caros e menos acessíveis do ponto de vista da personalização. Operacionalmente, as bijuterias são produzidas de diferentes materiais, como aço, plástico, madeira, pedras, resina, latão, sementes, bambu, dentre outros, o que denota menores custos de produção. Em termos mercadológicos, são mais facilmente comercializadas. Isso significa, segundo os autores, que as bijuterias - quando comparadas às joias - conseguem, com maior facilidade, suprir as necessidades dos consumidores e é tendente em acompanhar a moda, uma vez que são mais fáceis de serem produzidas em padrões ilimitados de design. Nas palavras de Modanez et al. (2009, p. 151), "foi necessário o impulso da moda para dar o prestígio necessário para tornar esse consumo relevante".

Isso ocorre, segundo Whelan et al. (2016), porque o consumo é resultado de efeitos de cognição, percepção e comportamento, regulados, por exemplo, pela sugestão - isto é, repetição ou manutenção da memória -, cuja moda tem um papel central de "sugerir" aquilo que as pessoas devem consumir ou fazer. Para os autores, não apenas as sugestões explicitas têm algum resultado no comportamento de consumo, mas o contexto social e as influências midiáticas produzem efeitos contínuos nas pessoas, especialmente no que diz respeito ao consumo nãotradicional; ou seja, aquilo que não é habitual ao consumidor, pode se tornar um padrão de consumo dada a presença de gatilhos associativos - por exemplo, uma emoção (ver, WATSON; SPENCE, 2007) ou um valor (ver, QUEIROGA et al., 2006) -, levando, inclusive a comportamento de consumo impulsivo.

Não obstante, Casals (2014) é enfática em ressaltar que a capacidade de imitação/inovação criativa no setor de bijuterias é justificada por sua expectativa comercial: um tipo de consumidor que busca diferenciação por qualidade, em um cenário de produto semelhante e 
preço similar. O alinhamento a essa característica do mercado pode indicar o sucesso ou fracasso do negócio (ver, DAUD; RABELLO, 2007; COBRA, 2009; KOTLER; KELLER, 2013). Neste limiar, Zambon e Anunciação (2014, p. 43) acreditam que "as estratégias do setor de bijuterias têm sido construídas considerando um pacto, de natureza tácita, que busca incorporar as necessidades do contexto empresarial local, que é coordenado por uma associação de produtores", justamente, devido a essa consideração obvia de que o consumidor de bijuterias busca a padronização associada à diferenciação.

Sob essa ótica, deve-se demarcar que o mercado tem estimulado o setor de bijuteria a estratégias que se concentram nas necessidades dos consumidores pela singularidade do consumo, cuja sensação do consumidor ao comprar é a de que o produto adquirido é algo especial, único e valioso (ver, JANG et al., 2016). Noronha et al. (2017) explicam que a solução para isso é a produção de bijuterias de forma artesanal, que, no entanto, exige um esforço de trabalho altamente desgastante, uma vez que a produção não é artística ou artesanal no sentido lúdico-cultural, mas padronizada para que cada peça produzida seja diferente - singular.

Tal cenário revela que o setor de bijuterias brasileiro é passível de oportunidades de negócio, mas que cresce desordenadamente, especialmente pela falta de posicionamento estratégico por parte das empresas, que advém predominantemente pela necessidade de informações mais robustas sobre o funcionamento e estrutura de mercado (SOUSA, 2015). Assim, o presente estudo reafirma tal necessidade e foca-se na investigação do comportamento de consumidoras de bijuterias, seguindo os procedimentos de pesquisa detalhados na próxima seção.

\section{Métodos}

\section{Tipo de pesquisa}

Em termos metodológicos, este estudo se delineou em caráter descritivo na maneira de conduzir a pesquisa e com abordagem quantitativa no modo de análise, cujo objetivo foi investigar o comportamento de consumidoras de bijuterias, no que diz respeito a perfil, hábitos de consumo e motivações de compra. A pesquisa descritiva associada a modelos quantitativos de análise, segundo Malhotra (2011), é traçada pelo estabelecimento de relações entre variáveis de uma amostra e determina sua relação com fenômenos ou elementos circundantes, descrevendoos para proporcionar uma visão específica do problema, neste caso, a necessidade de compreensão do comportamento consumidor no setor de bijuterias quanto à segmentação sociodemográfica e psicográfica.

\section{Instrumentos, Amostra e Coleta de dados}

Para a realização do estudo foram utilizados dois instrumentos de pesquisa, sendo um questionário sociodemográfico e um inventário de comportamentos de consumo aplicado ao setor de bijuterias, conforme modelos prévios apresentados por Malhotra (2011). O questionário sociodemográfico visou conhecer e caracterizar as participantes da pesquisa, contando com as seguintes questões: Faixa Etária, Escolaridade e Renda Familiar. Por sua vez, considerando critérios normativos de instrumentalização (ver, COOPER; SCHINDLER, 2011; MALHOTRA, 2011), o inventário de comportamentos de consumo contou com 7 itens, tendo-se 1 item em formato ordinal (do tipo ipsativa), 3 itens em formato nominal (do tipo múltipla escolha), 1 outro item em formato dicotômico e 2 itens em formato escalar (tipo Likert de 5 pontos, variando de $1=$ Nada Importante à $5=$ Muito Importante), que buscaram investigar junto aos participantes, respectivamente:

- $\quad$ Preferência de compra;

- $\quad$ Frequência de compra;

- $\quad$ Quantidade de produtos por compra;

- $\quad$ Nível justo de preços de compra;

- Acompanhamento de lançamentos;

- $\quad$ Fatores que influenciam na compra;

- Fatores que influenciam a escolha da loja (local de compra).

Os instrumentos de pesquisa foram aplicados de forma não probabilística e intencional, individualmente, junto a 202 mulheres brasileiras consumidoras de bijuterias - com idade média entre 15 e 35 anos (78\% da amostra). As participantes da pesquisa foram abordadas pessoalmente - nos turnos manhã, tarde e noite - em frente a lojas de bijuterias em 2 shoppings centers na cidade de Maceió, no estado 
de Alagoas, ou por meio eletrônico via Google Docs, desde que atendessem ao critério de participação: já ter comprado bijuterias para uso próprio.

Além disso, as participantes foram esclarecidas sobre o anonimato e sigilo de suas respostas, sendo garantido o caráter voluntário da participação, bem como, $\mathrm{o}$ respeito às diretrizes éticas que regem a pesquisa com seres humanos. Utilizou-se o método survey, com margem de erro amostral padrão de $\pm 6,9 \%$.

\section{Análises e Procedimentos}

Os dados foram tabulados e processados no software Statistical Package for Social Sciences (IBM/SPSS 21). Inicialmente, procedeu-se às análises de estatística descritiva de parametrização simples (p.ex., frequência, percentual, média e desvio-padrão). As análises iniciais foram utilizadas para identificar e apresentar o perfil das participantes, seus hábitos de consumo e suas motivações de compra, em consonância ao objetivo proposto.

Por sua vez, visando encontrar simetrias e/ou diferenças entre o comportamento das consumidoras participantes da pesquisa, utilizou-se como critério a estratificação por classe social. Para preencher os requisitos básicos de operacionalização de pesquisa, as participantes do estudo foram divididas em dois subgrupos conforme a renda familiar, considerando especificações do Centro de Políticas Sociais da Fundação Getúlio Vargas (NERI, 2012). Dividiuse a amostra em quartis e determinou-se o ponto médio como critério de corte. Assim, a sub-amostra 1 foi representada pelas participantes com menor poder aquisitivo (renda líquida até $\mathrm{R} \$ 2.896,00$ ) que compõem as classes $\mathrm{C}$ e $\mathrm{D}$; e a sub-amostra 2 foi representada pelas participantes com maior poder aquisitivo (renda líquida acima de $\mathrm{R} \$ 2.896,00$ ), as classes A e B.

Assim, foi procedido o teste $\mathrm{t}$ de Student, para amostras independentes, na comparação dos escores médios da sub-amostra 1 (classes $\mathrm{C}$ e D) e da subamostra 2 (classes A e B) nos itens:

i. $\quad$ Nível justo de preços de compra;

ii. Frequência de compra;

iii. Quantidade de produtos por compra; iv. Escolaridade;
v. Renda Familiar.

Partiu-se do pressuposto de que as classes teriam comportamentos de consumo diferentes em função das disparidades de renda - valor estatisticamente significativo a um nível de probabilidade associada de $\mathrm{p}<0,05$ (bilateral). O teste $\mathrm{t}$ de Student é um teste paramétrico e para sua utilização é necessário que se cumpram as pressuposições de que os dados têm distribuição normal nos dois conjuntos e exista homogeneidade em suas variâncias (BARBETTA, 2006). O teste de Levene não detectou homogeneidade nas variâncias dositens. Portanto, utilizaram-se os dados em primeira opção, ou seja, sem homogeneidade das variâncias para o teste $\mathrm{t}$ em termos de sua significância $(p<0,05)$. Especificamente para o teste $t$ de student, o item Escolaridade foi operacionalizado em uma escala do tipo Likert, variando de 1 (escolaridade muito baixa) a 5 (escolaridade muito alta), considerando cada um dos 5 níveis de escolaridade indicados no questionário sociodemográfico.

As análises foram utilizadas para apresentar os resultados da pesquisa. Foi utilizada como base analítica a evidenciação empírica indutiva, em função da maneira como os dados foram processados e como os resultados foram interpretados à luz dos objetivos propostos (ver, HAIR; BABIN; MONEY; SAMOUEL, 2005; COOPER; SCHINDLER, 2011).

\section{Resultados e Discussão}

Considerando os objetivos propostos, associados aos procedimentos metodológicos descritos anteriormente, apresentar-se-ão os resultados da pesquisa e suas respectivas discussões em quatro seções, a saber: (1) Caracterização do perfil das participantes; (2) Hábitos de consumo; e (3) Motivações de compras; e (4) Comparação entre as participantes das classes C e D e as participantes das classes A e B.

\section{Caracterização do Perfil das Participantes}

Inicialmente, é relevante destacar que boa parte dos comportamentos de consumo, em geral, pode ser explicada a partir da caracterização sociodemográfica (MEDEIROS; CRUZ, 2006; PETER; OLSON, 2009;

RPCA | Rio de Janeiro | v.10 | n. 4 | out./dez. 2016 | 130-147 | 135 
SOLOMON, 2013), sendo estes comportamentos influenciados - isto é, orientados ou motivados também por diferentes constructos psicológicos, como atitudes (ver, MANAKTOLA; JAUHARI, 2007), valores humanos (ver, ALLEN, 2001; QUEIROGA et al., 2006) e traços de personalidade (ver, HAUGTVEDT; PETTY; CACIOPPO, 1992; FRAJ; MATINEZ, 2006). Nesta seção, serão analisados: faixa etária, nível de escolaridade e renda familiar.

Em relação à variável faixa etária, as participantes da pesquisa estiveram em uma amplitude de idade entre 15 e 74 anos de idade, estando $78 \%$ da amostra com idade média entre 15 e 35 anos, $12 \%$ entre 35 e 54 anos e $10 \%$ entre 55 e 74 anos. Os dados indicam, a priori, duas situações distintas, porém indissociáveis. Primeiro, em termos de faixa etária, as consumidoras de bijuterias participantes da pesquisa se estendem desde o público adolescente até o público idoso; o que indica que, mercadologicamente, é possível trabalhar diferentes modelos de abordagem, campanha promocional e/ ou características de produto, de acordo com fases da vida [ideia defendida por Gouveia et al. (2015), de que as pessoas mudam gostos e preferências devido a alterações na estrutura valorativa durante o decorrer da vida]. Segundo, em contraponto, houve prevalência de um público mais jovem (entre 15 e 35 anos), de modo que ratifica, em parte, premissas levantadas por pesquisas nesse âmbito (p.ex., VINENT, 2000; BERTONCELLO; CRESCITELLI, 2009; SCHLÜCKING, 2011; CASALS, 2014).

Por sua vez, a variável nível de escolaridade, conforme os resultados indicados na Tabela 1 , não apresenta concentração prevalente.

Tabela 1. Nível de Escolaridade das Participantes da Pesquisa

\begin{tabular}{lcc}
\hline Nível de Escolaridade & Frequência & $\mathbf{( \% )}$ \\
\cline { 1 - 1 } Nível médio incompleto & 10 & $4,95 \%$ \\
Nível médio completo & 65 & $32,17 \%$ \\
Nível superior incompleto & 50 & $24,75 \%$ \\
Nível superior completo & 42 & $20,80 \%$ \\
Pós-graduação & 35 & $17,33 \%$ \\
\hline \multicolumn{1}{l}{ Total } & $\mathbf{2 0 2}$ & $\mathbf{1 0 0 \%}$ \\
\hline
\end{tabular}

Fonte: Dados da pesquisa.
Apesar disso, a maior porcentagem $(32,17 \%)$ para o item Nível médio completo (sem a entrada no ensino superior) - mesmo considerando que as participantes se encontram em maioria com idade entre 15 e 34 anos, isto é, comumente entre o início do ensino médio e o término do ensino superior - dá indícios de um grupo de participantes com provável descontinuidade dos estudos formais.

Em complemento, seguindo com a análise do perfil socioeconômico das participantes da pesquisa, verificou-se que a distribuição da renda líquida familiar se concentrou entre $\mathrm{R} \$ 1.449,00$ e $\mathrm{R} \$ 2.896,00$, indicado por $41,09 \%$ da amostra, conforme a Tabela 2 .

Tabela 2 . Renda Líquida Familiar

\begin{tabular}{lcc}
\hline Renda Líquida Familiar & Frequência & $\mathbf{( \% )}$ \\
\hline Até R\$ 1.448,00 & 18 & $8,91 \%$ \\
Entre R\$ 1.449,00 e R \$ 2.896,00 & 83 & $41,09 \%$ \\
Entre R $2.897,00$ e R $\$ 4.344,00$ & 51 & $25,24 \%$ \\
Entre R 4.345,00 e R \$ 8.000,00 & 31 & $15,34 \%$ \\
Acima de R\$ 8.000,00 & 19 & $9,40 \%$ \\
\hline Total & $\mathbf{2 0 2}$ & $\mathbf{1 0 0 \%}$ \\
\hline
\end{tabular}

Fonte: Dados da pesquisa.

Os resultados mostram, para além de uma realidade evidente, que o perfil das consumidoras de bijuterias não destaca caracterização particular. No entanto, os dados corroboram análises anteriores (p.ex., RODRIGUES, 2013; GOULART; RIBEIRO; CARVALHO, 2014), uma vez que indicam uma leve prevalência do público jovem da Classe C. O viés de análise é puramente indutivo, mas os dados revelam congruência com pesquisas anteriormente realizadas - reforçando o aspecto de senso-comum vindo da avalição dos empresários do setor - (ver, FARACO, 2010), seguindo uma estrutura semelhante.

\section{Hábitos de Consumo de Bijuterias}

Hábitos e preferências de consumo, geralmente, podem ser controlados pela moda (COBRA, 2007) ou por uma flexão sensorial da memória - chamado de conforto cognitivo (KAHNEMAN, 2012). Conforme Peter e Olson (2009), o nível de inclinação (predisposição) ao consumo de determinado produto ou grupo de produtos é modificado transculturalmente, no que diz 
respeito à frequência e quantidade de compra, à preferência por produtos específicos e à relação preço justo versus valor do produto.

De tal modo, buscou-se, inicialmente, identificar os tipos de produtos que, caracterizados como bijuterias e acessórios, eram mais adquiridos pelas participantes da pesquisa, conforme a ordem de preferência de compra (ver Figura 1). Embora os aspectos contextuais (moda) e individuais (processos cognitivos) não possam ser acessados aqui - em detrimento do questionário utilizado na pesquisa -, as análises que se seguem ressaltam a ideia de que, diferente da compra de uma casa ou de um carro, o comportamento de compra de bijuterias pode ou não se configurar por uma predisposição ou ação previamente planejada, uma vez que esse é um tipo de consumo supérfluo (que transpassa as necessidades básicas de sobrevivência) e comumente de baixo custo para o consumidor (ver, SOUSA, 2015), o que poderia ser balizado, por exemplo, a partir de uma necessidade de estima momentânea ou impulsividade (ver, MANAKTOLA; JAUHARI, 2007; SOLOMON, 2013).

Figura 1. Preferência de compra (Bijuterias e Acessórios)

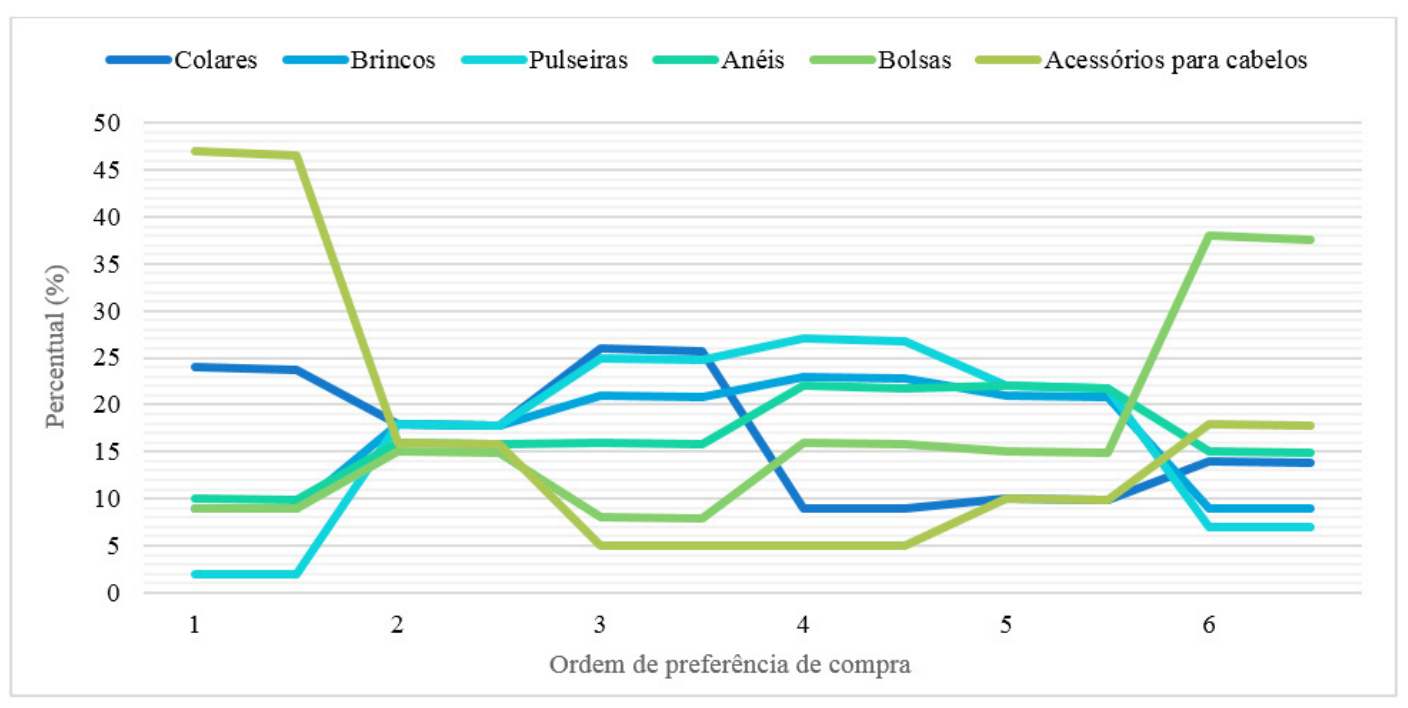

Fonte: Dados da pesquisa.

A Figura 1 apresenta as bijuterias e acessórios conforme a ordem de preferência de compras das participantes da pesquisa. Conforme se analisa, as Bolsas são os acessórios de maior intenção de compra (38\% da amostra), enquanto os acessórios de cabelo são os de menor intenção de compra ( $47 \%$ da amostra). Entretanto, uma vez que as bolsas variavelmente podem ser consideradas acessório específico e não necessariamente um hábito de consumo de bijuteria, vale ressaltar a segunda e a terceira maior preferência de compra, a qual concentra quase toda a amostra investigada em, respectivamente: Brincos (21\% e 23\%), Pulseiras (22\% e 22\%) e Anéis (22\% e $27 \%)$.

Por conseguinte, avaliou-se o quanto as participantes da pesquisa atribuíam como preço justo a pagar por cada um dos produtos indicados na análise anterior: colares, brincos, pulseias, anéis, bolsas e acessórios para cabelo. Tradicionalmente, segundo Kotler e Keller (2013), o preço é o fator chave determinante para a escolha de um produto pelo consumidor, em especial por determinar o quanto o consumidor atribui valor ao produto. Vários outros fatores denotam igual importância, porém o preço ainda é um dos elementos fundamentais na determinação da participação de mercado.

Analisando a Tabela 3, percebe-se que a maioria das consumidoras de bijuterias não está disposta a pagar preços altos por bijuterias, especialmente aos acessórios para cabelo, em que 80,2\% da amostra indicou que o preço justo para este item seriam valores abaixo de $\mathrm{R} \$ 25,00$. Por sua vez, as bolsas foram a única exceção, visto que $96,04 \%$ da amostra se mostrou disposta a pagar mais de $\mathrm{R} \$ 60,00$ - possivelmente pelas mesmas razões dadas na discussão da Figura 1. 
Tabela 3 . Preço justo a pagar por cada produto

\begin{tabular}{lccc|c|c|c|c}
\hline \multirow{2}{*}{\multicolumn{1}{c}{ Produtos }} & \multicolumn{2}{c}{ Menos de R\$ 25,00 } & \multicolumn{2}{c}{ Entre R\$ 26,00 e R\$ 60,00 } & \multicolumn{2}{c}{ Acima de R\$ 60,00 } \\
\cline { 2 - 7 } & Frequência & $\mathbf{( \% )}$ & Frequência & $\mathbf{( \% )}$ & Frequência & $\mathbf{( \% )}$ \\
\hline Colares & 40 & $19,80 \%$ & 118 & $58,42 \%$ & 44 & $21,78 \%$ \\
Brincos & 74 & $36,63 \%$ & 126 & $62,38 \%$ & 2 & $0,99 \%$ \\
Pulseiras & 86 & $42,57 \%$ & 88 & $43,56 \%$ & 28 & $13,86 \%$ \\
Anéis & 80 & $39,60 \%$ & 94 & $46,53 \%$ & 28 & $13,86 \%$ \\
Bolsas & 0 & $0,00 \%$ & 8 & $3,97 \%$ & 194 & $96,04 \%$ \\
Acessórios para cabelo & 162 & $80,20 \%$ & 40 & $19,80 \%$ & 0 & $0,00 \%$ \\
\hline
\end{tabular}

Fonte: Dados da pesquisa.

Ademais, verifica-se que as participantes da pesquisa indicaram que, comumente, os preços justos para bijuterias em geral (colares, brincos, pulseiras e anéis) estão entre $\mathrm{R} \$ 26,00$ e $\mathrm{R} \$ 60,00$. Basicamente, o preço esclarece o posicionamento e o valor do produto para o consumidor (ver, KOTLER; KELLER, 2013). Logo, precificar no setor de bijuterias pode ser o determinante para a obtenção ou a evasão do cliente, dado que o consumo de bijuteria não está apenas na intenção de compra, mas na oportunidade de compra associada ao preço que o consumidor acredita ser adequado - isto é, preço justo e que não comprometa a sua capacidade financeira naquele momento.

Em sequência, avaliou-se a frequência de compras de bijuterias. $\mathrm{Na}$ Tabela 4, observa-se que a maioria das participantes da pesquisa $(59,41 \%$ da amostra) compram bijuterias de 1 a 2 vezes por mês. Apesar disso, quase que a totalidade da amostra afirma comprar bijuterias até 5 vezes por mês. Isso pode significar que a bijuteria é tratada como commodity de baixo custo e que o seu consumo é controlado por variáveis aleatórias e pela acessibilidade do consumidor ao produto.

Tabela 4 . Frequência de compra de bijuterias

\begin{tabular}{lcc}
\hline \multicolumn{1}{c}{ Frequência de Compra } & $\mathbf{N}$ & \multicolumn{1}{c}{$\mathbf{( \% )}$} \\
\hline 1 a 2 vezes ao mês & 120 & $59,41 \%$ \\
3 a 5 vezes ao mês & 52 & $25,74 \%$ \\
Acima de 5 vezes ao mês & 20 & $9,90 \%$ \\
Esporadicamente (entre 2 e 3 meses) & 10 & $4,95 \%$ \\
\hline Total & $\mathbf{2 0 2}$ & $\mathbf{1 0 0 \%}$ \\
\hline
\end{tabular}

Fonte: Dados da pesquisa.

Hisrich, Peters e Shepherd (2014) advertem para o fato de que uma alta rotatividade de clientes pode ser prejudicial para a saúde financeira da empresa, o que ocorre, em geral, com a comercialização de bijuterias e acessórios. De tal modo, atrair e fidelizar clientes se tornam desafios iminentes para empresas do setor de bijuterias. Embora a possibilidade de lucro seja evidente para o setor, acessibilidade em termos de localização e preço são ainda supra determinantes, segundo o Instituto Brasileiro de Gemas e Metais Preciosos (IBGM, 2014).

Visando esclarecer o exposto, buscou-se analisar o tipo de loja (estabelecimento) em que as consumidoras de bijuterias preferiam realizar compras. Conforme a Tabela 5, vale destacar que as preferencias centrais estiveram concentradas boutiques $(37,15)$ e lojas de departamento $(19,80)$ - estabelecimentos encontrados comumente em shoppings centers. Tal distribuição pode ser vista como um ponto positivo para novos negócios, visto que as consumidoras de bijuterias têm demonstrado prevalência à comodidade. Para Daud e Rabello (2007), quando a experiência de compra se torna cômoda para o consumidor, este se sente atraído, criando um ciclo virtuoso de 
lealdade, propaganda boca-a-boca, reconhecimento na comunidade, aumento nas vendas e possibilidades de lucro.

Tabela 5 . Tipo de Loja em que costuma comprar Bijuterias

\begin{tabular}{|c|c|c|}
\hline Tipo de Loja & Frequência & $(\%)$ \\
\hline Quiosque & 31 & $15,34 \%$ \\
\hline Boutique & 75 & $37,15 \%$ \\
\hline Joalheria & 33 & $16,33 \%$ \\
\hline Camelô & 23 & $11,38 \%$ \\
\hline Loja de departamento & 40 & $19,80 \%$ \\
\hline Total & 202 & $100 \%$ \\
\hline
\end{tabular}

Fonte: Dados da pesquisa.

Contudo, as respostas apresentaram certa variabilidade, dado que as participantes da pesquisa mostraram preferências que denotam diferentes perfis de compra. Por exemplo, é possível que consumidores de joalherias (16,33\%) apresentem hábitos de compra diferentes de consumidores de camelôs $(11,38 \%)$.

Em complemento, foi analisada a quantidade de produto adquirida em cada compra realizada (Tabela 6).

Tabela 6. Quantidade de produto por compra

\begin{tabular}{lcc}
\hline \multicolumn{1}{c}{ Quantidade } & Frequência & $\mathbf{( \% )}$ \\
\hline 1 produto & 16 & $7,92 \%$ \\
2 produtos & 82 & $40,59 \%$ \\
3 produtos & 52 & $25,74 \%$ \\
4 produtos & 28 & $13,84 \%$ \\
Acima de 4 produtos & 24 & $11,90 \%$ \\
\hline Total & $\mathbf{2 0 2}$ & $\mathbf{1 0 0} \%$ \\
\hline
\end{tabular}

Fonte: Dados da pesquisa.

A maioria das participantes da pesquisa afirmaram adquirir mais de 1 produto por compra, dos quais $40,59 \%$ das consumidoras de bijuterias revelaram comprar geralmente 2 produtos por cada compra. Assim, retomando a Tabela 4, depreende-se que o hábito de compra das consumidoras de bijuterias é o de pequenas quantidades (até 3 produtos por compra representam $74,25 \%$ da amostra) em diversas vezes (pelo menos 2 vezes por mês 95,05\% da amostra compra bijuteria).

Em finalização à avaliação dos hábitos de consumo, analisou-se se as consumidoras de bijuterias acompanham ou não as novidades do setor (Tabela 7).

Tabela 7 . Se acompanha os lançamentos nas lojas de bijuterias

\begin{tabular}{l|cc}
\hline \multicolumn{1}{c}{ Alternativas } & Frequência & $\mathbf{( \% )}$ \\
\hline Sim & 98 & $48,51 \%$ \\
Não & 104 & $51,49 \%$ \\
\hline Total & $\mathbf{2 0 2}$ & $\mathbf{1 0 0 , 0 0 \%}$ \\
\hline
\end{tabular}

Fonte: Dados da pesquisa.

Os resultados denotam que houve certo equilíbrio nas respostas das participantes da pesquisa, não existindo uma sobreposição prevalente. Apesar disso, embora clientes que acompanham lançamentos de moda nem sempre representam garantia de compra, este dado é de real relevância para a compreensão da probabilidade de novos produtos conseguirem ser inseridos no mercado. Cobra (2007) reforça que a aceitação geral da moda exerce poder coercitivo sobre os consumidores. Por sua vez, Kahneman (2012) explica que o "efeito priming" - influência de um evento antecedente ao evento consequente -, no caso o acompanhamento das novidades, gera uma intenção inconsciente que possivelmente leva o consumidor ao desejo de compra. Assim, ressalta-se a necessidade de explorar o contato mais próximo com o cliente, enfatizando a divulgação de novidades, uma vez que "o poder relativo pertence a quem está o mais próximo possível do consumidor, física, psicológica e emocionalmente" (DAUD; RABELLO, 2007, p. 17).

\section{Motivações de Compra}

Quanto às motivações de compra, procurou-se identificar principais fatores que as consumidoras de bijuterias valorizam no processo de compra. A análise auxilia na explicação de elementos estruturantes que perfazem as escolhas no momento de compra, como preferências, necessidades ou valores. 
Na Figura 2, são apresentados os fatores que influenciam na compra de bijuterias em uma escala de 5 pontos, variando de 1 (fator nada importante) a 5 (fator muito importante). Os resultados mostram que as participantes da pesquisa compram bijuterias, prioritariamente, "quando os preços e condições de pagamento são satisfatórios" (50\% indicou este ser um fator muito importante) ou "quando estão precisando" (50\% indicou este ser um fator muito importante).

Figura 2 . Fatores que influenciam na compra

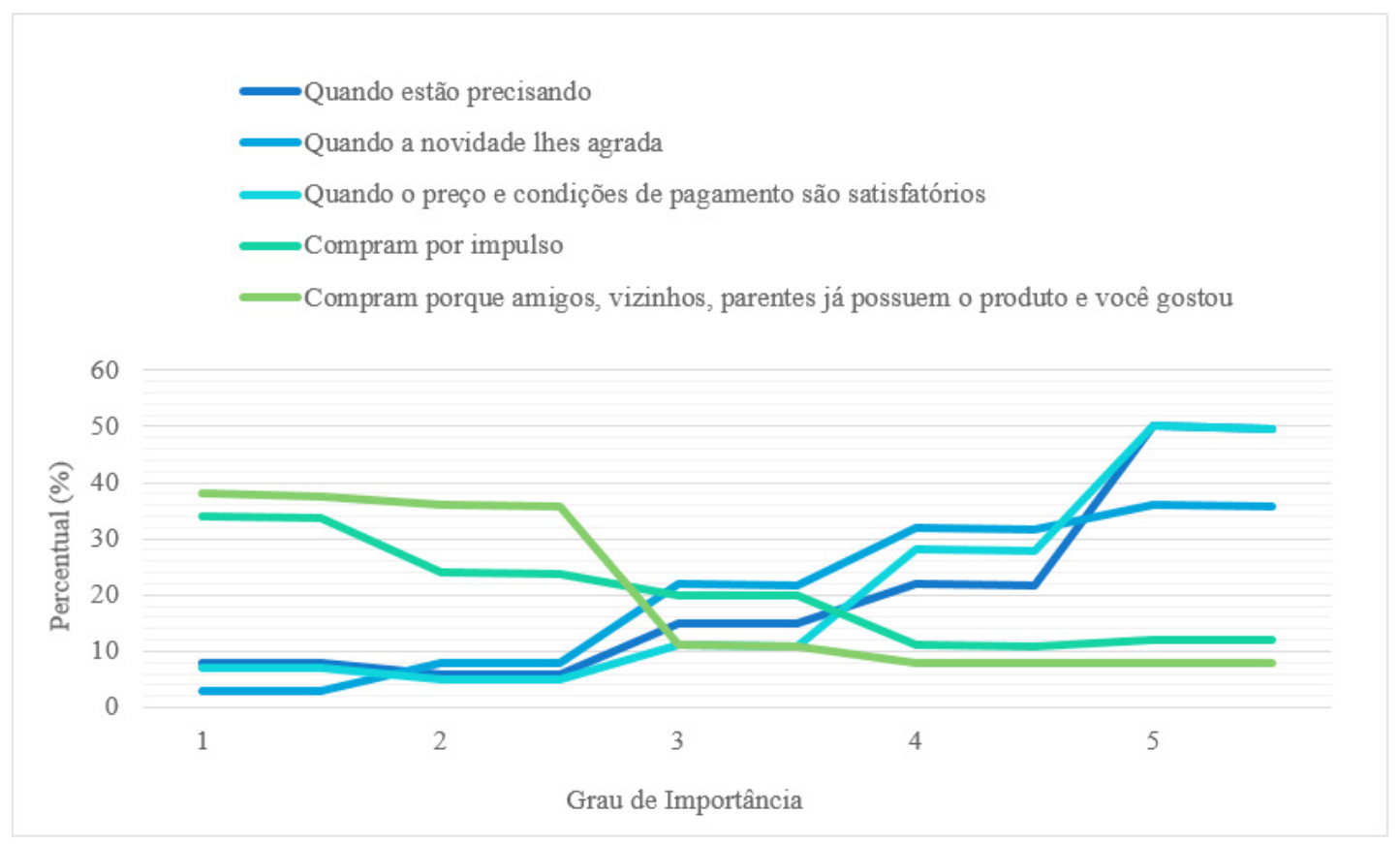

Fonte: Dados da pesquisa.

Embora as compras não planejadas, ou compras por impulso, sejam mais frequentes no varejo por se tratar de um processo decisório mais emocional (ver, WATSON; SPENCE, 2007), as participantes da pesquisa afirmaram que a impulsividade não é um fator que tenha influência sobre a compra de bijuterias - 39\% alegaram ser "nada importante" (escore 1) e 38\% alegaram ser "pouco importante (escore 2) no processo de compra.

Alegar necessidade ou que o preço e a condição de pagamento são satisfatórios não anula a impulsividade da compra. O baixo endosso para as compras por impulso pode indicar uma falsa impressão da respondente de que o seu sistema regulador e racional determina a sua vontade, quando sua intenção de compra, na verdade, está sendo determinada pelo seu sistema automático que torna em comportamento o desejo íntimo subjacente (ver, KAHNEMAN, 2012). Além disso, isso pode ser explicado pela desejabilidade social (ver GOUVEIA et al., 2009), ou seja, desejar ou responder aquilo que é melhor socialmente aceito. Logo, ser um consumidor por impulso não seria, socialmente, a melhor resposta que a respondente poderia estar fornecendo para a pesquisa.

Vale destacar que o fator menos influente no processo de compra para as participantes da pesquisa foi a indicação de amigos, vizinhos e parentes. $\mathrm{O}$ resultado contradiz dados do Serviço Brasileiro de Apoio às Micro e Pequenas Empresas (SEBRAE, 2014), os quais explicam que os consumidores comumente demonstram confiança nas indicações realizadas por pessoas próximas e/ou familiares. Para o estudo do Sebrae (2014), contato face-to-face, linguagem leve e convidativa e mensagens diretas costumam ser fundamentais e mais eficazes. Logo, ressalta-se a necessidade reflexão cuidadosa com a interpretação de ambos os resultados.

Complementarmente, conforme a Figura 3, foram avaliados os fatores que interferem na escolha de uma loja (local de compra), em uma escala de 5 pontos, variando de 1 (fator nada importante) a 5 (fator muito importante). 
Figura 3 . Fatores que influenciam a escolha da loja (local de compra)

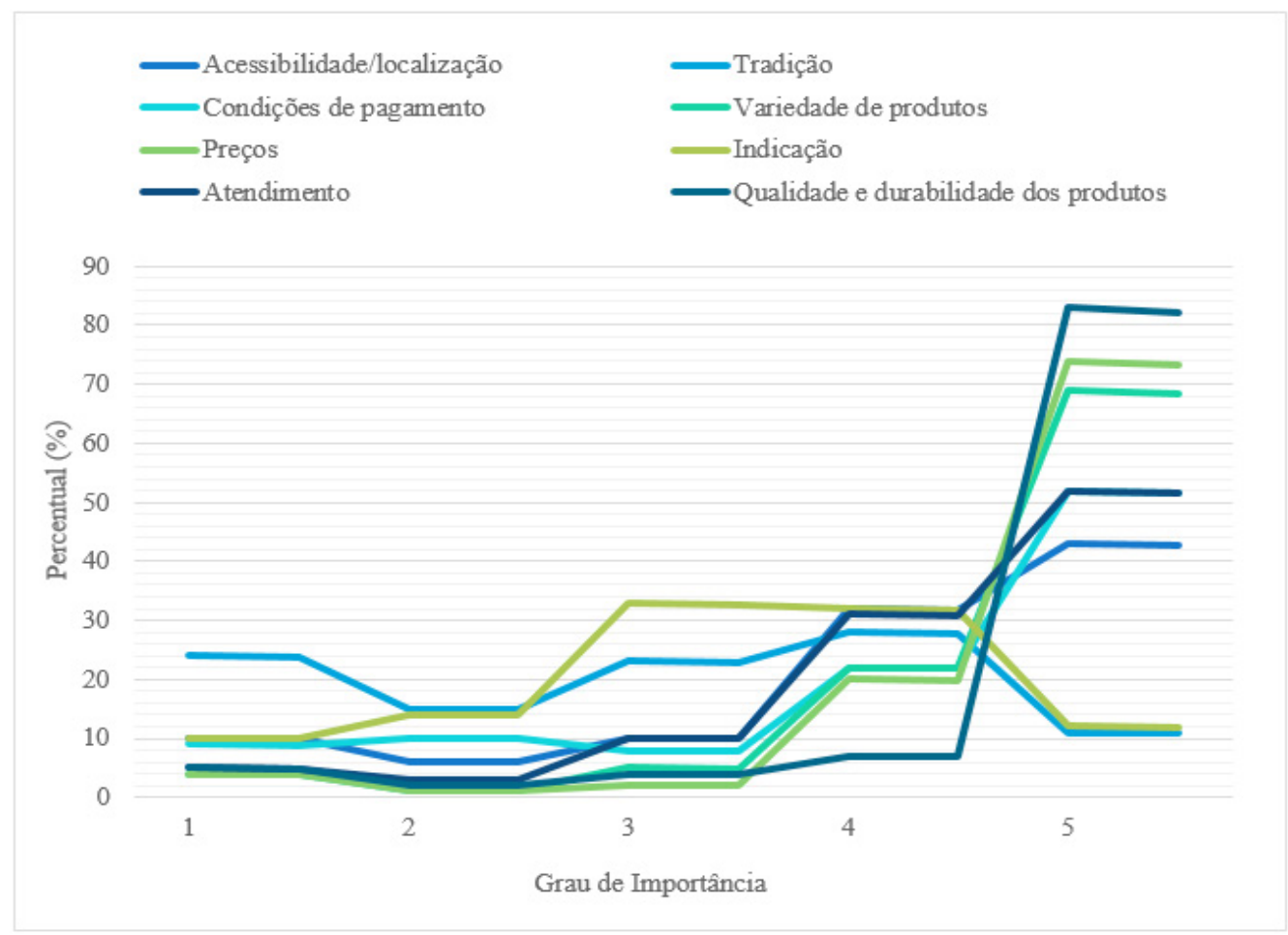

Fonte: Dados da pesquisa.

O principal fator que influencia na escolha do local de compra para as consumidoras de bijuterias foi a qualidade e a durabilidade dos produtos comercializados pelo estabelecimento (loja) escolhido ( $82 \%$ da amostra). Além disso, outros fatores foram também considerados como "muito importante" (escore 5): preço (73\%), variedade de produtos (68\%), condições de pagamento (51\%), qualidade do atendimento (51\%) e acessibilidade/localização (42,57\%). Assim como no item anterior, a indicação de lojas de bijuterias se manteve pouco importante ou neutro na escolha do local de compra. Esses dados são contundentes em ressaltar a necessidade de pesquisas de mercado no setor de bijuterias, visando encontrar com mais clareza como o setor e seus consumidores se comportam. O que já é possível perceber, é que as consumidoras de bijuterias são influencias por qualidade associada ao preço, conforme a literatura já vem defendendo (p.ex., PETER; OLSON, 2009; KOTLER; KELLER, 2013; SOLOMON, 2013).

\section{Comparação entre o público das classes C e D (sub-amostra 1) e 0 público das classes A e B (sub-amostra 2)}

Ao se analisar os hábitos de consumo e as motivações de compra, percebe-se uma ampla variabilidade nas respostas que, a priori, não denota a existência de alguma explicação específica. De tal modo, buscando-se encontrar simetrias e/ou diferenças entre o comportamento das consumidoras de bijuterias participantes da pesquisa, arbitrou-se a estratificação por classe social.

Ainda não há dados sobre o setor de bijuterias que pontue diferença de hábitos de consumo e motivações de compra entre as classes sociais, embora diversos autores e pesquisas (p.ex., BOURDIEU, 1983; CASTILHOS, 2007; PETER; OLSON, 2009; COBRA, 2012; SEBRAE, 2014) acreditem que existe diferença no comportamento de consumo entre classes sociais. Logo, conhecendo tais diferenças, é possível identificar o quanto determinadas variáveis podem influenciar direta e indiretamente os consumidores de bijuterias e o setor. 
Conforme detalhado na seção 3.3, as participantes da pesquisa foram divididas pela mediana em duas subamostras. A sub-amostra 1 foi caracterizada pelas participantes das Classes C e D ( $\mathrm{n}=101)$ e a sub-amostra 2 foi caracterizada pelas participantes das Classes A e B $(n=101)$, em que foram realizadas comparações entre as sub-amostras por meio do test $\mathrm{t}$ de student para amostras independentes.

Nas Tabelas 8 e 9, estão dispostos os parâmetros utilizados para analisar as diferenças entre valores das duas sub-amostras, em que são apresentadas as médias e seus respectivos desvios padrão (DP), o valor do teste t, os graus de liberdade, o valor da significância $(p)$ e as diferenças das médias tendo como base um intervalo de confiança de $95 \%$.

Na Tabela 8, avaliou-se se havia diferença entre as sub-amostras quanto à valoração de preço justo a pagar por cada produto.

Tabela 8 . Preço justo que clientes pagariam por cada produto

\begin{tabular}{|c|c|c|c|c|c|c|c|c|}
\hline \multirow[b]{2}{*}{ Produtos } & \multicolumn{2}{|c|}{ Sub-Amostra 1} & \multicolumn{2}{|c|}{ Sub-Amostra 2} & \multicolumn{4}{|c|}{ Estatísticas } \\
\hline & Média & DP & Média & DP & $\mathbf{t}$ & gl & $\mathrm{p}$ & $\begin{array}{c}\text { Diferença das médias } \\
\text { (IC 95\%) }\end{array}$ \\
\hline Colares & 2,00 & 0,648 & 2,02 & 0,583 & $-0,228$ & 200 & $0,820^{*}$ & $\begin{array}{c}0,087 \\
\left(-0,191 \_0,151\right)\end{array}$ \\
\hline Brincos & 1,64 & 0,502 & 1,62 & 0,563 & 0,264 & 200 & $0,792 *$ & $\begin{array}{c}0,075 \\
\left(-0,128 \_0,168\right)\end{array}$ \\
\hline Pulseiras & 1,71 & 0,698 & 1,86 & 0,649 & $-1,567$ & 200 & $0,119 *$ & $\begin{array}{c}0,095 \\
\left(-0,335 \_0,038\right)\end{array}$ \\
\hline Anéis & 1,74 & 0,688 & 1,97 & 0,685 & $-2,358$ & 200 & $0,019 * *$ & $\begin{array}{c}0,097 \\
\left(-0,418{ }_{-}-0,037\right)\end{array}$ \\
\hline Bolsas & 2,96 & 0,196 & 2,97 & 0,171 & $-0,383$ & 200 & $0,702 *$ & $\begin{array}{c}0,026 \\
\left(-0,061 \_0,041\right)\end{array}$ \\
\hline Acessórios para cabelo & 1,20 & 0,400 & 1,29 & 0,455 & $-1,478$ & 200 & $0,141 *$ & $\begin{array}{c}0,060 \\
\left(-0,208 \_0,030\right)\end{array}$ \\
\hline
\end{tabular}

Fonte: Dados da pesquisa.

* valores $\mathrm{p}>0,05 ; * *$ valores $\mathrm{p}<0,05$.

Com os resultados da Tabela 8 , verifica-se que não houve diferença significativa entre as médias das subamostras 1 e 2, exceto para o item Anéis que demonstrou uma pequena diferença nas médias $(t=-2,358 ; p<$ 0,05). Isso denota que, basicamente, as classes A e B acreditam que bijuterias têm o mesmo valor relativo que as classes $\mathrm{C}$ e D. Logo, depreende-se que as classes mais altas não estariam dispostas a pagar mais caro por um produto que reconhecem como mais barato. Por exemplo, o mesmo tipo de bijuteria vendido em uma boutique não poderia apresentar preços muito mais altos do que em um quiosque.

Por sua vez, a Tabela 9 compara as sub-amostras em relação à frequência de compra, à quantidade de produtos por compra, à escolaridade e à renda familiar. 
Tabela 9. Frequência de compra, quantidade de produtos por compra, escolaridade e renda familiar

\begin{tabular}{|c|c|c|c|c|c|c|c|c|}
\hline \multirow[b]{2}{*}{ Fatores } & \multicolumn{2}{|c|}{ Sub-Amostra 1} & \multicolumn{2}{|c|}{ Sub-Amostra 2} & \multicolumn{4}{|c|}{ Estatísticas } \\
\hline & Média & DP & Média & DP & $\mathbf{t}$ & g1 & $\mathrm{p}$ & $\begin{array}{l}\text { Diferença das } \\
\text { médias (IC } \\
95 \% \text { ) }\end{array}$ \\
\hline Frequência de Compra & 2,57 & 1,395 & 2,47 & 1,446 & 0,545 & 200 & $0,587^{*}$ & $\begin{array}{c}0,200 \\
\left(-0,285 \_0,503\right)\end{array}$ \\
\hline $\begin{array}{l}\text { Quantidade de produtos por } \\
\text { Compra }\end{array}$ & 2,81 & 1,146 & 2,67 & 1,217 & 0,833 & 200 & $0,406^{*}$ & $\begin{array}{c}0,166 \\
\left(-0,190 \_0,467\right)\end{array}$ \\
\hline Escolaridade & 2,42 & 0,495 & 2,52 & 0,540 & $-1,493$ & 200 & $0,137^{*}$ & $\begin{array}{c}0,073 \\
\left(-0,253 \_0,035\right)\end{array}$ \\
\hline Renda familiar & $2.102,1$ & 595,4 & $5.807,4$ & $2.905,6$ & $-12,555$ & 200 & $0,000 * * *$ & $\begin{array}{c}3.705,32 \\
(-4.287,28- \\
-3.123,36)\end{array}$ \\
\hline
\end{tabular}

Fonte: Dados da pesquisa.

$*$ valores $\mathrm{p}>0,05 ; * *$ valores $\mathrm{p}<0,05 ; * * *$ valores $\mathrm{p}<0,001$

Naturalmente, a renda familiar mostrou uma diferença significativa alta $(t=-12,555 ; \mathrm{p}=0,000)$ entre a subamostra 1 (classes C e D) e a sub-amostra 2 (classes A e B), o que corrobora a prerrogativa adotada nesta pesquisa: há consumidoras de bijuteria em todas as classes e seus respectivos poder de compra e capacidade financeira (avaliados por meio da renda familiar) são diferentes.

No entanto, de forma contraintuitiva, os resultados não evidenciaram diferença significativa $(p>0,05)$ entre as sub-amostras 1 e 2 em relação à frequência de compra, à quantidade de produtos por compra e à escolaridade. Isto é, embora as rendas familiares sejam diferentes - o que pode implicar em diferentes locais de residência, diferentes locais de compra e/ou diferentes pontos de acesso -, as Classes C e D em relação às Classes $\mathrm{A}$ e $\mathrm{B}$ apresentam hábitos de consumo de bijuterias semelhantes.

Não obstante, conforme Peter e Olson (2009), a diferença entre a classe baixa e a classe alta, em termos de consumo, se torna mais evidente para produtos de luxo. Quando se trata de produtos usuais (comuns ou de baixo valor), a classe baixa costuma consumir tanto quanto as classes mais altas. Os autores explicam que:

\footnotetext{
É possível considerar o nível de renda como subcultura porque pessoas de diferentes níveis de renda tendem a ter valores, comportamentos e estilos de vida bem distintos. (...) embora a subcultura de alta renda constitua um excelente mercado para artigos de luxo de alta qualidade, somente uma entre cinco famílias encontra-se nessa categoria. O mercado de massa é de baixa renda, o que em parte explica o enorme sucesso de lojas de descontos como a Wal-Mart (PETER; OLSON, 2009, p. 326).
}

Os resultados aqui apresentados corroboram o fato de que a renda familiar não influencia hábitos de consumo no mercado de bijuterias, nem segmenta de forma totalizadora uma subcultura. Provavelmente, a renda é determinante no segmento de produtos de luxo (joias e carros importados), porém, o consumo de bijuterias é baseado na cultura de massa. Notadamente, o consumo é definido, em grande parte, por elementos como idade, grupo étnico ou região (ver, PETER OLSON, 2009; SOLOMON, 2013). No caso do setor de bijuterias - assim como o setor de lingeries, por exemplo -, o gênero é a variável definidora, dado que o seu consumo é predominante por mulheres. 
Além disso, a renda da população não aumenta necessariamente com o passar do tempo. Também, afirmam Peter e Olson (2009), o mercado de baixa renda em geral é bastante lucrativo porque consome muito e de forma massificada. Logo, depreende-se que estratégias adotadas para o setor de bijuterias devam seguir uma abordagem universal e abrangente, seguindo preceitos do marketing global-digital (ver, KOTLER; KELLER, 2013).

\section{Considerações Finais}

Em consonância ao objetivo deste estudo - investigar o comportamento de consumidoras de bijuterias, no que diz respeito a perfil, hábitos de consumo e motivações de compra -, foram encontrados resultados pontuais e padrões de resposta que podem ser considerados relevantes, uma vez que há um decesso de estudos sobre o setor de bijuterias. Assim, tais resultados fornecem maior conhecimento sobre esse tipo de mercado e norteiam possíveis estratégias para empresas do setor, bem como na viabilização de novos negócios.

De modo sumarizado, os resultados denotam a predominância, em consumidoras de bijuterias, dos seguintes aspectos:

- As consumidoras têm predominantemente entre 15 e 35 anos de idade;

- Fazer parte da Classe A, B, C ou D não interfere nos hábitos de consumo de bijuterias;

- $\quad$ Preferem comprar em boutiques e lojas de departamento;

- Compram bijuterias, geralmente, quando os preços e condições de pagamento são satisfatórios ou quando estão precisando;

Porém:

- Costumam ir mais de uma vez por mês em lojas de bijuterias;

- $\quad$ Levam mais de um tipo de produto;

- $\quad$ Priorizam preço e durabilidade.
A partir disso, este estudo permite o acesso profícuo à estrutura das relações de compra e esclarece elementos específicos que perfazem possíveis padrões de consumo no mercado brasileiro de bijuterias. Além disso, depreende-se que as respostas indicam demanda real por bijuterias e que, em virtude disso, são estabelecidas diretrizes a respeito do consumo de bijuterias.

A forte presença das bijuterias na moda contemporânea tem se tornado comum e cresce em termos de personalização, diferenciação e qualidade, que são indispensáveis para consumidoras de todas as classes sociais. $\mathrm{O}$ setor se revela economicamente e mercadologicamente viável. Por esse viés, o conhecimento e a compreensão do comportamento de compra do consumidor de bijuterias são fundamentais para a alavancagem do setor em termos de maturidade e consolidação.

Sob esse aspecto, a literatura destaca três aspectos que se alinham aos resultados obtidos: (1) o consumo de bijuterias é remetido ao efeito da moda, cujo objetivo é criar sensações de consumo cuja prioridade é uma "suposta" necessidade; e por essa razão, o consumo de bijuterias é remetido a uma faixa etária - que costuma utilizar (e necessitar de) adereços no seu cotidiano ou a uma condição de mercado - preço (quanto mais barata a bijuteria, maior quantidade de itens é levada, independente da renda); (2) a cultura é determinante na adoção de bijuterias, visto que o uso de adereços caracteriza estereótipos, preferências, momentos de vida etc., em que as principais influências não estão ligadas a classe social ou a nível escolaridade; (3) a produção de bijuterias tem seguido uma estrutura voltada para a padronização e a singularidade, que compõem a qualidade percebida pelo consumidor avaliada de forma tanto objetiva, quanto subjetiva, por atributos como durabilidade, características técnicas, inovações e aparência.

De tal modo, percebe-se que o uso de técnicas mercadológicas ajustado aos preceitos da moda denota um avanço para o setor de bijuterias (produtos e comerciantes), considerando um viés gerencial. Logo, a principal contribuição deste trabalho está em demonstrar como o setor de bijuterias pode compreender o perfil do consumidor para desenvolver estratégias de marketing mais profícuas, difundindo e incentivando, também, a exploração acadêmica de temáticas relacionadas ao setor. 
Este estudo, então, visa contribuir com conhecimentos específicos e dados complementares sobre o setor de bijuterias, que tem sido tão pouco investigado na literatura nacional. Basicamente, foram encontrados apenas 5 artigos em periódicos científicos nacionais estratificados na área da Administração, Ciências Contábeis e Turismo (ver, DI GIULIO, 2007; PALMA et al., 2014; SILVA et al., 2014; ZAMBON; ANUNCIAÇÃO, 2014; CUNHA; CUNHA; MONTE, 2015) e 4 dissertações de mestrado nas áreas de Administração (ver, CAETANO, 2006; SOUSA, 2015), Ciências Contábeis (ver, ZAMBON; ANUNCIAÇÃO, 2014) e Engenharia de Produção (ver, SILVA, 2004), que tratavam direta ou indiretamente do setor de bijuterias.

Portanto, dada às limitações deste estudo - pequeno número amostral, instrumentação que impossibilita o uso de análises mais robustas (regressão múltipla ou modelagem por equações estruturais) e aprofundamento teórico limitado quanto aos constructos comportamentais -, incentivamos novas pesquisas sobre o comportamento do consumidor no setor de bijuterias, de forma que se avaliem variáveis psicossociais (p.ex., valores, atitudes, traços disposicionais, emoções) associadas às intenções de compra (com destaque ao aspecto da impulsividade). Ademais, vale ressaltar que o setor de bijuterias está em evidente crescimento, o que revela uma necessidade também de estudos sobre capacidade inovadora, padrões mercadológicos e estrutura financeira nas empresas do setor.

\section{Referências}

ALBERTON, J. R. Benefícios de custos em empresas participantes de arranjos produtivos locais: um estudo em empresas do arranjo produtivo local de joias folheadas de Guaporé/RS. 2011. 145 f. Dissertação (Mestrado em Ciências Contábeis) Universidade do Vale do Rio dos Sinos, São Leopoldo, 2011.

ALLEN, M. W. A practical method for uncovering the direct and indirect relationships between human values and consumer purchases. Journal of Consumer Marketing, v. 18, n. 2, p. 102-120, 2001.

BARBET'TA, P. A. Estatística aplicada às ciências sociais. Florianópolis: Ed. UFSC, 2006.
BERTONCELLO, S. T.; CRESCITELLI, E.

Comportamento do jovem consumidor mediante as diversas alternativas de mídia. Revista Brasileira de Pesquisas de Marketing, Opinião e Mídia, v. 3, p. 8-19, 2009.

BOURDIEU, P. Gostos de classe e estilos de vida. In: BOURDIEU, P. (Ed.). Sociologia. São Paulo: Ática, 1983. p. 82-121.

CAETANO, C. R. K. Um estudo do processo de internacionalização dirigido à pequena empresa e à contribuição do Arranjo Produtivo Local de Semi-Jóias e Bijuterias desenvolvido na região de Limeira, Estado de São Paulo. 2006. 130 f. Dissertação (Mestrado em Administração) Universidade Cidade de São Paulo, São Paulo, 2006.

CASALS, L. B. Pla de negoci - shop online de bijuteria personalitzada. 2014. $56 \mathrm{f}$. Monografia (Bacharelado em Administració i Gestió de la Innovació) - Universitat Pompeu Fabra, Barcelona, 2014.

CASTILHOS, R. B. Subindo o morro: consumo, posição social e distinção entre famílias de classes populares. 2007. 205 f. Dissertação (Mestrado em Administração) - Universidade Federal do Rio Grande do Sul, Porto Alegre, 2007.

COBRA, M. Marketing e moda. São Paulo: Senac, 2007.

COBRA, M. Administração de marketing no

Brasil. 3. ed. Rio de Janeiro: Elsevier, 2009.

DAUD, M.; RABELLO, W. Marketing de varejo: como incrementar resultados com a prestação de serviços. Porto Alegre: Bookman, 2007.

COOPER, D. R.; SCHINDLER, P. S. Métodos de pesquisa em administração. 10. ed. Porto Alegre: Bookman, 2011.

CUNHA, G. I. C.; CUNHA, J. I. C.; MONTE, W. $\mathrm{S}$. As mídias sociais e as empresas de moda. Revista Brasileira de Pesquisas de Marketing, Opinião e Mídia, v. 16, p. 28-45, 2015.

DI GIULIO, G. Pólo de jóias e bijuterias cresce com informalidade e pouca inovação. Inovação Unimep, v. 3, n. 2, p. 42-45, 2007.

FARACO, G. de A. A indústria de joias e bijuterias: um estudo de caso da empresa Gabriela Faraco acessórios de moda. 2010. 76 f. Monografia 
(Graduação em Ciências Econômicas) - Universidade Federal de Santa Catarina, Florianópolis, 2010.

FIGUEIREDO, V. C. N.; TRAPÉ, A. Z. O uso de cianeto na produção de bijuterias e folheados: proposta de investigação sobre a saúde das trabalhadoras em domicílio no município de Limeira. Revista de Ciências Médicas, v. 16, n. 2, p. 97-107, 2007.

FRAJ, E.; MARTINEZ, E. Influence of personality on ecological consumer behaviour. Journal of Consumer Behaviour, v. 5, n. 3, p. 167-181, 2006.

GOULART, J.; RIBEIRO, R.; CARVALHO,

$\mathrm{H}$. Elementos culturais brasileiros aplicados em acessórios femininos. In: Seminário Acadêmico da Associação de Pesquisadores e Estudantes Brasileiros na Catalunha, 2014, 19., Barcelona. Anais...

Barcelona: APEC, 2014.

GOULART, J.; CARVALHO, H.; RIBEIRO, R.

Brazilian cultural elements applied to the creation of a brand for female fashion accessories. In: International Fashion and Design Congress - CIMODE, 2014, 2., Milan. Anais... Milão: Scuola del Design Politecnico di Milano, 2014.

GOUVEIA, V. V.; VIONE, K. C.; MILFONT, T. L.; FISCHER, R. Patterns of value change during the life span: Some evidence from a functional approach to values. Personality \& Social Psychology Bulletin, v. 41, n. 9, p. 1276-1290, 2015.

GOUVEIA, V. V.; GUERRA, V. M.; SOUSA, D. M. F.; SANTOS, W. S.; COSTA, J. de M. Escala de desejabilidade social de Marlowe-Crowne: evidências de sua validade fatorial e consistência interna.

Avaliação Psicológica, v. 8, n. 1, p. 87-98, 2009.

HAIR, J. F., Jr.; BABIN, B.; MONEY, A. H.; SAMOUEL, P. Fundamentos de métodos de pesquisa em administração. Porto Alegre: Bookman, 2005.

HAUGTVEDT, C. P.; PETTY, R. E.; CACIOPPO, J. T. Need for cognition and advertising: Understanding the role of personality variables in consumer behavior. Journal of Consumer Psychology, v. 1, n. 3, p. 239260, 1992.

HISRICH, R. D.; PETERS, M. P.; SHEPHERD, D. Empreendedorismo. 9. ed. Porto Alegre: AMGH, 2014.

IBGM - Instituto Brasileiro de Gemas e Metais
Preciosos. Informe técnico - folheados e bijuterias. Brasília: IBGM, 2014.

JANG, W. E.; KO, Y. J.; MORRIS, J. D.; CHANG, Y. Scarcity Message Effects on Consumption Behavior: Limited Edition Product Considerations. Psychology \& Marketing, v. 32, n. 10, p. 989-1001, 2015.

KAHNEMAN, D. Rápido e devagar: duas formas de pensar. Rio de Janeiro: Objetiva, 2012.

KOTLER, P.; KELLER, K. L. Administração de marketing. 14. ed. São Paulo: Pearson Prentice Hall, 2013.

LACORTE, L. E. C.; VILELA, R. A. G.; SILVA, R. D. C.; CHIESA, A. M.; TULIO, E. S.; FRANCO, R. R.; BRAVO, E. S. The knots of the child labor eradication network within the jewelry and costume jewelry production in Limeira, São Paulo, Brazil. Revista Brasileira de Saúde Ocupacional, v. 38, n. 128, p. 199-215, 2013.

MALHOTRA, N. K. Pesquisa de marketing: foco na decisão. 3. ed. São Paulo: Pearson Prentice Hall, 2011.

MANAKTOLA, K.; JAUHARI, V. Exploring consumer attitude and behaviour towards green practices in the lodging industry in India. International Journal of Contemporary Hospitality Management, v. 19, n. 5, p. 364-377, 2007.

MEDEIROS, J. F.; CRUZ, C. M. L. Comportamento do consumidor: fatores que influenciam no processo de decisão de compra dos consumidores. Teoria e Evidência Económica, v. 14, Ed. especial, p. $167-$ 190, 2006.

MODANEZ, P. S.; CAMARGO, S. H. C. R. V.; SPERS, V. R. E.; SACOMANO NETO, M. Segmentação psicográfica e estilos de vida de consumidores de venda direta por catálogo. Revista Brasileira de Marketing, v. 8, n. 1, p. 138-163, 2009.

NERI, M. C. (Coord.). De volta ao país do futuro: projeções, crise europeia e a nova classe média. Rio de Janeiro: FGV/CPS, 2012.

NORONHA, T. A.; SANTOS, H. B.; FARIA, K. C.; ABRAÃO, C. A.; CASTRO, G. G. Prevalência de queixa álgica musculoesquelética em trabalhadores de empresa de bijuteria. Cinergis, v. 18, n. 1, p. 397-402, 2017. 
OLIVEIRA, L. F.; GIL, A. C. O conglomerado comercial da rua 25 de Março, em São Paulo: uma região socialmente construída. Revista de Estudos Sociais, v. 13, n. 25, p. 118-137, 2014.

PALMA, E. P.; GOMES, C. M.; KNEIPP, J. M.; ROSA, L. A. B. Estratégias de negócios sustentáveis e desempenho exportador: uma análise em empresas do setor de gemas e joias. Revista Brasileira de Gestão de Negócios, v. 16, n. 50, p. 25-42, 2014.

PETER, J. P.; OLSON, J. C. Comportamento do consumidor e estratégia de marketing. 8. ed. São Paulo: McGraw-Hill, 2009.

PIMENTEL, T. D.; CARRIERI, A. P.; SILVA, A. R. L.; PERREIRA, R. D.; PIMENTEL, M. P. C. As representações e as práticas sociais das "sacoleiras" na feira hippie de belo horizonte: a representação social de empreendedoras de pequenos negócios. Revista da Micro e Pequena Empresa, v. 5, n. 2, p. 60-76, 2011.

QUEIROGA, F.; GOUVEIA, V. V.; COUTINHO, M. D. P. L.; PESSOA, V.; MEIRA, M. Intenção de comportamento socialmente responsável do consumidor: sua relação com os valores humanos básicos. Psico-USF, v. 11, n. 2, p. 239-248, 2006.

RENNÓ, L. C.; TEIXEIRA, D. J. O impacto do turismo nos hábitos de consumo de uma comunidade de pequeno porte. Turismo - Visão e Ação, v. 9, n. 2, p. 217-232, 2008.

RODRIGUES, G. F. Estudo da viabilidade comercial de criação de loja virtual para exportação de bijuterias para Edimburgo, Escócia. 2013. 23 f. Monografia (Bacharelado em Administração) - Universidade do Extremo Sul Catarinense, Criciúma, 2013.

SAMPAIO, S. E. K. Sistemas locais de produção: estudo de caso na indústria de jóias e bijuterias de Limeira (SP). 2002. 71 f. Monografia (Graduação em Economia) - Universidade Estadual de Campinas, Campinas, 2002.

SCHLÜCKING, E. W. Projeto de viabilidade econômico-financeira de um comércio varejista de peças para bijuteria no Bairro Trindade no município de Florianópolis. 2000. 115 f. Monografia (Bacharelado em Ciências Contábeis) Universidade Federal de Santa Catarina, Florianópolis, 2000 .

SEBRAE - Serviço Brasileiro de Apoio às Micro e
Pequenas Empresas. Moda: perfil de consumo das classes A e B. Brasília: SEBRAE, 2014.

SILVA, M. G. B. A organização sócio-espacial da pequena produção artesanal do sítio histórico de Olinda. In: Encontro da Associação Nacional de PósGraduação e Pesquisa em Planejamento Urbano e Regional, 2007, 12., Belém. Anais... Rio de Janeiro: UFRJ, 2007.

SILVA, I. R. Implementação de programa de melhoria de desempenho ambiental numa empresa de semijóias. 2004. 102 f. Dissertação (Mestrado em Engenharia de Produção) Universidade Paulista, São Paulo, 2004.

SILVA, R. S.; ARAÚJO, M. F.; FARINA, M. C.; SILVEIRA, M. A. P. Ações conjuntas e trocas de informações existentes entre pequenas lojas de um shopping atacadista de moda. Revista da Micro e Pequena Empresa, v. 8, n. 2, p. 38-53, 2014.

SOLOMON, M. R. O comportamento do consumidor: comprando, possuindo e sendo. 9. ed. Porto Alegre: Bookman, 2011.

SOUSA, C. S. S. Centro de inteligência competitiva: fator estratégico para a competitividade das PME - o caso do setor da bijuteria em LimeiraSP-Brasil. 2015. 79 f. Dissertação (Mestrado em Ciências Empresariais) - Instituto Politécnico de Setúbal, Setúbal, 2015.

VINENT, A. R. Projecte d'instal-lació de nau industrial dedicada a bijuteria. 2011. $127 \mathrm{f}$.

Dissertação (Mestrado em Electricitat) - Escola Universitària d'Enginyeria Tècnica Industrial de Barcelona, Barcelona, 2011.

WATSON, L.; SPENCE, M. T. Causes and consequences of emotions on consumer behaviour: A review and integrative cognitive appraisal theory. European Journal of Marketing, v. 41, n. 5/6, p. 487-511, 2007.

WHELAN, J.; GOODE, M. R.; COTTE, J.; THOMSON, M. Consumer Regulation Strategies: Attenuating the Effect of Consumer References in a Voting Context. Psychology \& Marketing, v. 33, n. 11, p. 899-916, 2016.

ZAMBON, A.; ANUNCIAÇÃO, P. Inteligência competitiva: percepções de valor no setor da bijuteria. Revista Portuguesa e Brasileira de Gestão, v. 13, n. 2, p. 41-60, 2014. 